\title{
Aktualisasi Jadwal Salat Sepanjang Masa Abu Muhammad Isa Mulieng Aceh
}

\author{
Ismail \& Husnaini* \\ Institut Agama Islam Negeri Lhokseumawe \\ *Email korespondensi: husnaini@iainlhokseumawe.ac.id
}

\begin{abstract}
This paper aims to explain the actualization of one of the prayer schedules that are still guided by the people of Aceh. Prayer schedules circulating in the community are of various types and forms, patterns of preparation and accuracy also vary. This type of research uses a qualitative approach with the documentation method as a data collection technique The all-time prayer schedule of Abu Muhammad Isa work compiled in 1984 was very contemporary in his time and included in the type of conversion prayer schedule for the surrounding area and guided by the West Indonesia Time zone $105^{\circ}$ (GMT + 7) in accordance with the Indonesian Presidential Decree. No. 243 of 1963. When compared with the results of the computational calculation, the prayer schedule is slower around 2 minutes than it should. This prayer schedule can be guided within a radius of 55.4 kilometers from the point of calculation, because it uses the value of ibktiyat 2 minutes and can still be used for all time because until now the resulting difference is only in seconds.
\end{abstract}

Keywords: Prayer Time, Aceh, Abu Muhammad Isa Mulieng

\begin{abstract}
Abstrak
Penelitian ini bertujuan untuk menjelaskan aktualisasi salah satu jadwal salat yang masih dipedomani oleh masyarakat Aceh, jadwal salat yang beredar di masyarakat beragam jenis dan bentuknya, pola penyusunan dan akurasi juga berbeda-beda. Jenis penelitian ini menggunakan pendekatan kualitatif dengan metode dokumentasi sebagai teknik pengumpulan data. Jadwal salat sepanjang masa karya Abu Muhammada Isa yang disusun pada tabun 1984 sangat aktual dimasanya dan termasuk dalam jenis jadwal salat konversi untuk daerah sekitarnya dan berpedoman kepada zona Waktu Indonesia Barat $105^{\circ}$ (GMT + 7) yang sesuai dengan Kepres RI. No. 243 Tahun 1963. Bila dibandingkan dengan hasil perbitungan kontomporer, jadwal salat ini lebih lambat sekitar 2 menit dari yang seharusnya. Jadwal salat ini dapat dipedomani dalam radius 55,4 kilometer dari titik perhitungan, karena menggunakan nilai ibktiyat 2 menit dan masih terus bisa digunakan untuk sepanjang masa dikarenakan sampai saat ini selisih yang dihasilkan hanya dalam sekala detik.
\end{abstract}

Kata Kunci: Jadwal salat, Aceh, Abu Muhammad Isa Mulieng

\section{A. Pendahuluan}

Sejauh ini, kajian tentang waktu salat telah banyak dilakukan oleh beberapa peneliti. Habibullah Ritonga dan Arwin Juli Rakhmadi Butar-Butar telah mengupas bagaimana peran ilmu falak dalam masalah penetuan waktu salat. Adapun Ismail 
telah mengkaji tentang metode penentuan waktu salat dalam perspektif ilmu falak. Begitu pun Dahlia Haliah Ma'un telah menguraikan tentang perpindahan waktu salat dari makna syariat ke dalam kaidah astronomi. Sementara Muhammad Hidayat telah menjelaskan penyebab perbedaan hasil perhitungan waktu salat dari satu lokasi dengan lokasi lainnya.

Beberapa penelitian yang membahas tentang jadwal salat antara lain Suroya (2013) tentang akurasi jadwal salat sepanjang masa karya Saa'doeddin Jambek. ${ }^{1}$ Hal yang sama dilakukan oleh Encep Abdul Rojak, Amrullah Hayatuddin, dan Muhammad Yunus (2017) tentang konsekuensi ketinggian tempat terhadap jadwal waktu salat di Kota Bandung. ${ }^{2}$ Begitu pun Dahlia Haliah Ma'un (2015) mendeskripsikan pemaknaan waktu shalat dari bahasa al-Quran dan Sunnah ke dalam kaidah-kaidah astronomi, sehingga waktu shalat dapat dengan mudah dihisab dan ditentukan, tanpa harus merukyah fenomena matahari setiap akan melaksanakan shalat. ${ }^{3}$ Dari beberapa kajian tersebut, tampaknya belum ada yang membahas tentang jadwal waktu salat sepanjang masa karya Abu Muhammad Isa Mulieng. Kajian ini menjadi penting dalam ilmu falak, selain dapat memberikan informasi tentang jadwal waktu salat yang masih beredar dalam masyarakat Indonesia, juga berguna dalam menganalisa jenis atau bentuk jadwal waktu salat yang ideal di masa sekarang.

Abu Muhammad Isa merupakan salah seorang ahli falak yang sangat berpengaruh dalam masyarakat Aceh khususnya dalam bidang ilmu falak. Salah satu kontribusi untuk masyarakat Aceh, khususnya bagi masyarakat Aceh Utara adalah jadwal salat sepanjang masa yang disusun pada tahun 1984 silam, namun sampai saat ini masih banyak didapati di beberapa masjid di Aceh Utara dan Kota Lhokseumawe. Jadwal salat sepanjang masa tersebut pada awalnya disusun dengan tulisan tangan, kemudian diketik ulang dan dicetak, dibingkai oleh masyarakat agar

${ }^{1}$ Nila Suroya, Uji Akurasi Pedoman Waktu Shalat Sepanjang Masa Karya Saädoéddin Djambek, skripsi, Semarang: IAIN Walisongo, 2013

2 Encep Abdul Rojak, Amrullah Hayatuddin, dan Muhammad Yunus, "Koreksi Ketinggian Tempat terhadap Fikih Waktu Salat: Analisis Jadwal Waktu Salat Kota Bandung”, Al-Abkam, 27, no. 2, 2017

3 Dahlia Haliah Ma’un, "Waktu Shalat: Pemaknaan Syar'i ke dalam Kaidah Astronomi”, Istinbath: Jurnal Hukum Islam, 14, no. 2, 2015 
mudah dan indah saat ditempel di dinding masjid, bahkan sampai saat ini sudah ada yang mencetak dengan desain warna dalam motif yang lebih indah.

Bagi masyarakat umum, jadwal salat menjadi suatu yang sangat dibutuhkan, karena dengan adanya jadwal waktu salat dapat memudahkan dalam melaksanakan salat disetiap kondisi dan lokasi tepat pada waktunya. Kondisi mendung tidak menjadi penghalang dalam mengetahui waktu salat bila jadwal salat telah tersedia, begitu pula lokasi tidak hanya terbatas di masjid, di rumah pun bisa melaksanakan salat di awal waktu bila berpedoman pada jadwal waktu salat. Namun bagaimana bila jadwal yang ada selama ini di masjid dan di rumah yang sudah menjadi rutinitas dan ketergantungan untuk dipedomani ternyata tidak sesuai dengan waktu salat yang semestinya. Oleh karena itu, kajian jadwal salat sepanjang masa karya Abu Muhammad Isa Mulieng akan menjadi sangat penting dalam mengetahui standar akurasi, aktualisasi, jenis dan bentuk jadwal waktu salat yang ideal untuk bisa dipedomani.

Abu Muhammad Isa Peureupok atau Abu Peuruepok begitu sapaan akrap masyarakat Aceh Utara terhadap pimpinan dayah (pesantren) Darul Falah merupakan ahli falak yang sangat kreatif dan inovatif di masanya. Sedangkan bagi masyarakat Aceh di luar Kabupaten Aceh Utara mengenal dengan sebutan Abu Muhammad Isa Muling, Mulieng dan Peuruepok saat ini merupakan dua nama desa yang dulu hanya dikenal dengan nama wilayah. Keahlian dalam bidang ilmu falak bisa dibuktikan lewat karya yang ditinggalkan seperti kitab Ibktisar al-falakyah dan jadwal salat sepanjang masa.

Nama lengkapnya Muhammad Isa bin Imum Buhan bin Teungku Imum Ibrahim bin Teungku Haji Lemak bin Teungku Haji Penghulu. Ibunya bernama Teungku Ni binti Teungku Leube Muda. Konon Abu Muhammad Isa merupakan darah Gujarat, India, dimana Teungku Haji Penghulu berasal dari Gujarat. Teungku Haji Penghulu bersama saudara dan teman-temannya merantau ke Aceh untuk berniaga dan berdakwah. ${ }^{4}$

\footnotetext{
${ }^{4}$ Murdani Bin Abdul Wahab, "Murdani bin Abdul Wahab: Biografi Ahli Falak Aceh; Teungku Muhammad Isa Mulieng, Aron. (1927-1997 M)," Murdani bin Abdul Wabab (blog), 2 Januari 2017, http://murdanialasyi.blogspot.com/2017/01/biografi-ahli-falak-aceh-teungku.html.
} 
Abu Mahammad Isa dilahirkan di Gampong (Desa) Meunasah Pulo Kayee Adang Keureuto yang sekarang dikenal dengan Gampong Pulo Blang Asan Kecamatan Syamtalira Aron Kabupaten Aceh Utara pada tahun 1927. Untuk tanggal, hari dan bulan lahir Abu Muhammad Isa tidak diketahui. Menurut hasil wawancara dengan Waled Mustafa M.Isa yang merupakan anaknya dan pimpinan dayah Darul Falah sekarang, tidak ada catatan dan informasi dari pihak keluarga yang mengingat hari, bulan dan tanggal Abu Muhammad Isa diahirkan, tahun kelahiran saja sebuah perkiraan keluarga dan dicatat dalam Kartu Tanda Penduduk (K'TP). Abu Muhammad Isa meninggalkan dunia yang fana ini di usia lebih kurang 69 tahun, yaitu pada malam Sabtu pukul 21.50 Wib 23 Ramadhan 1417 atau 31 Januari 1997 di rumah kediamannya. ${ }^{5}$

Abu Muhammad Isa mencicipi pendidikan umum pada sekolah belanda di Simpang Dama Keureutoe pada tahun 1939. Kemudian melanjutkan pada pendidikan Islam Bustanul Ma'arif Blang Jruen selesai pada tahun 1943. Selanjutnya Abu Muhammad Isa menenpuh pendidikan di Dayah Cot Trueng Bungkah Kecamatan Muara Batu Kabupaten Aceh Utara dengan pimpinan saat itu Abubakar Ali atau sering dipanggil Abu Cot Kuta (1896-1971). Setelah menimba ilmu agama lebih kurang lima tahun di Dayah tersebut, kemudian Abu Muhammad Isa pada tahun 1956 melanjutkan pendidikan di Dayah Ulee Titi Aceh Besar dengan pimpinan dayah saat itu Abu Ishak. Selain belajar ilmu-ilmu agama pada Abu Ishak, Abu Muhammad Isa sempat belajar dan mendalami ilmu falak pada Syekh Tsaman, Teungku Muhammad Shalih dan Abu Hasan Krueng Kale dengan salah satu kitab rujukannya yaitu Majmu' fi 'ilmi al-falaky karangan Said Syally. Inilah tiga guru Abu Muhammad Isa dalam bidang Imu Falak. ${ }^{6}$

Selanjutnya pada tahun 1957 Abu Muhammad Isa pindah ke Dayah Labuhan Haji Aceh Selatan dengan pimpinan Dayah saat itu Abuya Muhammad Wali AlKhalidy. Kemudian pada tahun 1960 Abu Muhammad Isa pindah ke Dayah

${ }^{5}$ Mustafa M. Isa, Biografi Muhammad Isa, 17 September 2019, Dayah Darul Falah, Aceh Utara.

${ }^{6}$ Murdani Bin Abdul Wahab, "Murdani bin Abdul Wahab: Biografi Ahli Falak Aceh; Teungku Muhammad Isa Mulieng, Aron. (1927-1997 M)," Murdani bin Abdul Wabab (blog), 2 Januari 2017, http://murdanialasyi.blogspot.com/2017/01/biografi-ahli-falak-aceh-teungku.html 
Thaiyibah Islamiyah Matang Geutoe Idi Cut Aceh Timur dengan pimpinan saat itu Abu Muhammad Thaib (1887-1967) dan pada tahun 1962 Abu Muhammad Isa pulang ke tempat kelahiran untuk mendirikan dayah yang diberi nama dengan Dayah Darul Falah.

Sebagai ulama yang ahli dalam bidang ilmu falak, Abu Muhammad Isa meninggalkan beberapa karya dalam bidang ilmu falak. Pertama kitab yang ditulis dengan tangan yang bernama Ikhtisharul al-falaky, kitab ini merupakan ringkasan tentang ilmu falak yang ditulis sebagai pedoman pembelajaran bagi yang belajar ilmu falak di Dayah Darul Falah saat itu. Kedua “jadwal waktu sembahyang untuk selama-lamanya", jadwal salat sepanjang masa ini pada awalnya ditulis tangan oleh Abu Muhammad Isa, kemudian untuk kepentingan praktis bagi masyarakat, diketik dan diperbanyak oleh masyarakat umum. Sampai saat ini masih banyak masjid di seputaran Aceh Utara yang masih menggunakannya. ${ }^{7}$

\section{B. Problematika Jadwal Salat di Indonesia}

Terminologi jadwal waktu salat saat ini sudah bergeser dari rukyat ke hisab, pergeseran ini disebabkan interpretasi ayat dan hadis didominasi oleh ilmu falak. Dalam terminologi rukyat, jadwal waktu salat, murni dimaknai sebagai peristiwa matahari sesuai dengan waktu peristiwa diamati. Waktu salat Zuhur saat tergelincir matahari, waktu Asar saat bayang suatu benda memiliki panjang yang sama, waktu Magrib saat terbenam matahari, waktu Isya saat hilang syafak merah dan waktu Subuh saat terbit fajar sadik. Sedangkan dalam terminologi hisab, jadwal waktu salat sudah dimaknai dengan posisi ketinggian matahari yang telah diformulasikan dalam algoritma dan telah diterjemahkan dalam tiga satuan waktu daerah yaitu, waktu Indonesia barat (WIB), waktu Indonesia tengah (WITA) dan waktu Indonesia timur (WIT). ${ }^{8}$

Jadwal waktu salat yang ada sekarang di Indonesia telah melalui perubahan dan perkembangan dalam tiga fase, hal ini sesuai dengan perkembangan dan

\footnotetext{
Utara.

7 Mustafa M. Isa, Biografi Muhammad Isa, 17 September 2019, Dayah Darul Falah, Aceh

8 Thomas Djamaluddin, Menggagas Fiqih Astronomi: Tela'ah Hisab-rukyat dan Pencarian Solusi Perbedaan Hari Raya., 1 ed. (Bandung: Kaki Langit, 2005), h. 137-139.
} 
pengembangai ilmu falak di Indonesia. Pada fase pertama waktu salat hanya berpedoman pada peredaran matahari yang dianggap tetap dalam setiap hari, terbit matahari selalu dianggap tetap pada jam 6.00, melewati garis meridian selalu jam 12.00 dan terbenam selalu jam 18.00. dari asumsi ini ditetapkan jadwal waktu salat Zuhur selalu jam 12.00, salat Asar jam 15.00, salat Magrib jam 18.00, salat Isya jam 19.15 dan salat Subuh 4.30. keadaan jadwal salat ini tetap dalam setiap tahun untuk suatu tempat dan waktu yang dipergunakan adalah standar waktu istiwak di tempat tersebut. ${ }^{9}$

Pada fase kedua, penentuan waktu salat masih juga menggunakan jam istiwak, namun pengetahuan terhadap peredaran matahari sudah berubah. Pada fase ini, peredaran matahari sudah dianggap tidak tetap, unsur deklinasi sudah mulai dipertimbangkan dalam menyusun waktu salat sehingga jadwal waktu salat dari hari ke hari sepanjang tahun akan berubah sesuai dengan perubahan data deklinasi matahari. Fase ketiga, jadwal waktu salat sudah menggunakan standar waktu daerah yaitu, WIB, WITA dan WIT. Data matahari seperti deklinasi dan perata waktu telah diambil dari data internasional seperti data yang diterbitkan oleh US Naval Observatory dan Royal Greenwich Observatory. Dengan menggunakan standar waktu daerah dalam penyusunan waktu salat, maka hasil perhitungan bisa dengan mudah dikonversikan untuk wilayah lain di seluruh Indonesia. Dengan alasan kebutuhan umat, sampai saat ini jadwal salat sistem komversi masih banyak beredar di Indonesia.

Bila berkaca pada tiga fase perkembangan waktu salat di Indonesia, hal yang terpenting dalam perubahan waktu salat adalah data matahari dan sistem waktu (zona waktu). Dua hal ini menjadi ciri khas pembeda jadwal waktu salat dalam setiap fase-fase perkembangannya. Selain dua hal tersebut, nilai ibtiyat juga menjadi sumbangan penting dalam keragaman hasil perhitungan waktu salat. Ihtiyat diartikan sebagai kehati-hatian dan sebagai suatu langkah pengamanan dengan cara menambah atau mengurangi hasil perhitungan yang berkisar antara 1 sampai 3

9 Departemen Agama RI, Pedoman Penentuan Jadwal Waktu Shalat Sepanjang Masa (Jakarta: Departemen Agama RI, 1994). h. 6-15. 
menit atau lebih. Setidaknya ada 3 tujuan ibtiyat dalam penyusunan jadwal salat. Pertama, agar hasil perhitungan dapat mencakupi daerah sekitarnya. Kedua, agar hasil perhitungan mudah digunakan dengan membulatkan satuan kecil dalam satuan menit waktu. Ketiga, agar menambah keyakinan bahwa waktu salat benarbenar dilaksanakan dalam waktunya. ${ }^{10}$

Sampai di sini dapat disimpulkan bahwa data matahari, zona waktu dan nilai ibtiyat terus menjadi perhatian dalam perkembangan penyempurnaan jadwal waktu salat di Indonesia. Data matahari yang sekarang diperbincangkan adalah data ketinggian matahari untuk waktu salat Isya dan Subuh, dimana posisi sekarang -18 derajat dianggap lambat untuk awal waktu Isya dan -20 derajat dianggap cepat untuk awal waktu Subuh. Banyak peneliti yang telah mencoba menemukan data baru dengan pendekatan baru untuk menemukan posisi matahari yang sebenarnya sebagai pertanda masuk waktu salat Isya dan Subuh. Diantaranya bisa dilihat penelitian Hamdani dan Laksmiyanti (2018) ${ }^{11}$ dengan menggunakan instrumen sky quality meter dalam menentukan data ketinggian matahari dan penelitian Nihayatur Rohmah (2011) ${ }^{12}$ dengan menggunakan instrumen fotometri.

Zona waktu atau waktu daerah menjadi salah satu warna dalam keragaman waktu salat di Indonesia. Sebagaimana diketahui bahwa zona waktu di Indonesia telah berubah sekitar sembilan kali. ${ }^{13}$ Perubaha zona waktu yang awalnya selalu mengacu kepada landasan ekonomi tidak pada landasan astronomis atau geografis menyebabkan para penyusun jadwal waktu salat lebih memilih standar waktu istiwak dan mengabaikan sistem zona waktu. Setelah keluar Keputusan Presiden Nomor 41 Tahun 1987 dengan menetapkan Indonesia dalam tiga zona waktu,

${ }^{10}$ Arwin Juli Rakhmadi Butar-butar, Waktu Salat Menurut Fikih dan Astronomi (Medan: LPPM UISU, 2016). H. 86.

${ }^{11}$ Fahmi Fatwa Rosyadi Satria Hamdani dan Laksmiyanti Annake Harijadi Noor, "The Dawn Sky Brightness Observations in the Preliminary Shubuh Prayer Time Determination," QIJIS (Qudus International Journal of Islamic Studies) 6, no. 1 (2 Juli 2018): 25-38, https://doi.org/10.21043/qijis.v1i1.2870.

12 Nihayatur Rohmah, "Penentuan Waktu Shalat Isya dan Shubuh dengan Aplikasi Fotometri." (Semarang, UIN Walisongo Semarang, 2011).

13 Akhina Z, "Zona Waktu di Indonesia Pernah Berubah 9 Kali. Gimana Ceritanya?," Good News From Indonesia, 17 Juni 2018, https://www.goodnewsfromindonesia.id/2018/06/17/zonawaktu-di-indonesia-pernah-berubah-9-kali-gimana-ceritanya. 
penentuan jadwal salat di Indonesia mulai mengacu kepada tiga zona tersebut, yaitu WIB, WITA dan WIT. ${ }^{14}$ Kalau acuan penetapan zona waktu berbasis geografis astronomis, jadwal waktu salat tetap sangat mudah ditentukan, walau dalam satu zona waktu sebagaimana sempat diisukan bahwa zona waktu Indonesia akan disatukan. ${ }^{15}$

Ibtiyat menjadi bahagian yang terpenting dalam menyusun jadwal waktu salat, khususnya dalam masalah radius dan pemberlakuan jadwal salat dari satu titik perhitungan ke beberapa daerah lain dengan alasan bisa mengaver dengan nilai ibtiyat. ${ }^{16}$ Konversi jadwal waktu salat yang masih mengabaikan nilai lintang tempat dan radius pemberlakuan waktu salat tidak selamanya tertutupi oleh nilai ihtiyat. Hasil penelitian Dahlia Haliah Ma'un (2013)17 menjelaskan batasan maksimal pemberlakuan waktu salat Asar dan Magrib tidak lebih dari $1^{\circ} 20^{\prime}$, salat Isya dan Subuh $1^{\circ}$, sedangkan untuk waktu Zuhur tidak ada pengaruh selisih nilai lintang tempat. Dari permasalahan radius pemberlakuan waktu salat, menarik diperhatikan apa yang diusulkan oleh Moelki Fahmi Ardliansyah (2017) ${ }^{18}$ dengan istilah titik tengah Kabupaten atau Kota dalam perhitungan waktu salat. Inilah sederetan problematika jadwal waktu salat di Indonesia yang terus mengalami perubahan mengikuti perkembangan ilmu pengetahuan dan teknologi di Indonesia.

\section{Jenis dan Bentuk Jadwal Salat di Indonesia}

Di era sekarang, kebutuhan dan ketergantungan terhadap jadwal salat masih sangat terasa dalam masyarakat, hampir bisa dipastikan tidak ada lagi yang melihat matahari saat akan melaksanakan salat di setiap waktu nya. Desain jadwal salat yang semakin canggih seperti dalam bentuk aplikasi yang mudah dipakai di era digital ini

\footnotetext{
14 Ahmad Junaidi, "Penyatuan Zona Waktu Indonesia Dan Implikasinya Pada Waktu Ibadah," Justicia Islamica 9, no. 2 (2012), https:// doi.org/10.21154/justicia.v9i2.350.

${ }^{15}$ Nailur Rahmi, "Penyatuan Zona Waktu dan Pengaruhnya terhadap Penetapan Awal Waktu Shalat," Juris 13, no. 1 (2014): 75-83, https://doi.org/10.1234/juris.v13i1.1130.

16 Jayusman Jayusman, "Akurasi Nilai Waktu Ihtiyath Dalam Perhitungan Awal Waktu Salat," ASAS 11, no. 01 (13 Agustus 2019): 78-93, https://doi.org/10.24042/asas.v11i01.4644.

${ }_{17}$ Dahlia Haliah Ma'un, "Jadwal Salat Sepanjang Masa Di Indonesia (Studi Akurasi Dan Batas Perbedaan Lintang Dalam Konversi Jadwal Salat)" (Disertasi, Semarang, IAIN Walisongo, 2013), http://eprints.walisongo.ac.id/23/.

18 Moelki Fahmi Ardliansyah, "Implementasi Titik Koordinat Tengah Kabupaten atau Kota Dalam Perhitungan Jadwal Waktu Salat," Al-Abkam 27, no. 2 (1 Desember 2017): 213, https://doi.org/10.21580/ahkam.2017.27.2.1981.
} 
membuat pemakai dituntut lebih untuk memahami tentang jadwal salat agar penggunaan jadwal salat tepat dan benar adanya. Dalam ilmu falak, penetuan waktu salat berdasarkan pada posisi matahari atau ketinggian matahari dari garis ufuk dalam sistem koordinat horizon. Atas dasar sistem koordinat ini algoritma waktu salat bisa disusun dengan bagus yang melahirkan jadwal salat sebagai pedoman dalam melaksanakan salat sehari-hari tanpa harus menunggu konfirmasi kepastian dengan peristiwa matahari sebagaimana informasi dalam Alquran dan hadis sebagai tuntunan dalam mengetahui masuk waktu salat. ${ }^{19}$

Jadwal yang beredar dalam masyarakat Indonesia masih belum seragam, baik dari segi jenisnya, bentuknya dan keakuratannya. Hal ini dipengaruhi oleh keterbatasan pemahaman penyusun, perbedaan pemahaman penyusun terhadap data matahari, dan konsep ibtiyat. Dalam penelitian Dahlia Haliah Ma'un dijelaskan ada beberapa jenis dan bentuk jadwal waktu salat yang beredar dalam masyarakat Indonesia. Secara umum ada dua jenis jadwal waktu salat di Indonesia. Pertama, jadwal waktu salat disusun di daerah tertentu dan berlaku hanya untuk wilayah tersebut (Jadwal salat tunggal). Kedua, jadwal waktu salat disusun di satu titik dan diberlakukan tidak hanya untuk satu daerah dimana titik perhitungan dilakukan, namun dikonversikan untuk wilayah lain (Jadwal salat konversi).

Bila mengacu kepada jenis konversi, bentuk jadwal waktu salat di Indonesia ada enam macam. Pertama jadwal waktu salat hanya berlaku untuk kota tertentu saja. Kedua jadwal waktu salat berlaku untuk kota tertentu dan mencantumkan jadwal konversi untuk daerah sekitarnya. Ketiga jadwal waktu salat berlaku untuk satu kota dan mencantumkan konversi untuk kota-kota besar lainnya. Keempat jadwal waktu salat yang diberlakukan pada selisih lintang 1 derajat. Kelima jadwal salat yang berlaku pada daerah-daerah selatan dengan selisih lintang 2 derajat. Keenam jadwal waktu salat yang berlaku untuk daerah selatan dengan selisih lintang 5 derajat. $^{20}$

19 Dahlia Haliah Ma'un, "Waktu Shalat: Pemaknaan Syar'I ke Dalam Kaidah Astronomi”, Istinbath: Jurnal Hukum Islam, 14, no. 2, 2015.

20 Dahlia Haliah Ma'un, "Jadwal Salat Sepanjang Masa Di Indonesia (Studi Akurasi Dan Batas Perbedaan Lintang Dalam Konversi Jadwal Salat)" (Disertasi, Semarang, IAIN Walisongo, 2013), http://eprints.walisongo.ac.id/23/. 
Jenis dan bentuk jadwal waktu salat tentunya tidak hanya terbatas pada yang telah disebutkan di atas. Penulis mengambil jenis dan bentuk jadwal waktu salat di atas karena hasil dari dari sebuah penelitian dan untuk menemukan jenis dan bentuk lain dari jadwal waktu salat harus melalui penelitian. Asumsi penulis, setidaknya ada 4 jenis jadwal salat yang pernah beredar di masyarakat Indonesia, yaitu jadwal salat tunggal, jadwal salat konversi, jadwal salat patokan zona waktu, dan jadwal salat patokan waktu lokal atau jam istiwak. Dari empat jenis jadwal salat ini tentunya bisa melahirkan bentuk yang lebih banyak.

Dalam menganalisa jadwal waktu salat, selain jenis dan bentuk jadwal waktu salat, ada satu hal yang sangat penting untuk diketahui yaitu radius pemberlakuan hasil perhitungan waktu salat dari titik perhitungan. Sekilas di atas dalam menjelaskan bentuk-bentuk jadwal salat sudah tergambarkan pola pemberlakuan hasil perhitungan, ada yang memberlakukan dengan pertimbangan bujur dan ada yang mempertimbangkan lintang dari 1 derajat sampai ada yang 5 derajat.

Jadi, secara astronomis, berapa luas radius berlaku hasil perhitungan waktu salat dari satu titik perhitungan? Untuk menjawab pertanyaan ini harus dijelaskan dulu konsep pembagian waktu di dunia. Waktu rata-rata yang diperlukan matahari dalam menempuh jarak 360 derajat adalah 24 jam. 360 derajat setara dengan panjang satu lingkaran bumi yaitu 40.000 kilometer.

Tabel 1. konsep pembagian waktu di dunia

\begin{tabular}{|c|l|}
\hline $360^{\circ}$ & 24 jam \\
\hline 24 & 1440 menit $\left(1^{\circ}=1440 / 360^{\circ}=4\right.$ menit $)$ \\
\hline $1^{\circ}$ & 4 menit \\
\hline $360^{\circ}$ & $400.000 \mathrm{~km}\left(1^{\circ}=40000 / 360^{\circ}=111,11 \mathrm{~km}\right)$ \\
\hline $1^{\circ}$ & $111,11 \mathrm{~km}$ \\
\hline 1 menit & $1 / 4^{\circ}$ \\
\hline 1 menit & $111,11 / 4=27,7 \mathrm{~km}^{21}$ \\
\hline
\end{tabular}

Jarak tempuh matahari dalam 1 menit adalah 27,7 km dari titik perhitungan. Logika dalam mencari radius pemberlakuan jadwal waktu salat, bila hasil perhitungan waktu salat di satu titik koordinat hanya berlaku untuk titik tersebut, maka ditambah ibtiyat 1 menit agar bisa berlaku dalam radius 27,7 km dari titik

21 Jayusman Jayusman, "Urgensi Ihtiyath dalam Perhitungan Awal Waktu Salat," AL'ADALAH 10, no. 1 (2012): 279-90, https://doi.org/10.24042/adalah.v10i1.269. 
koordinat. Bila ditambah nilai ibtiyat 2 menit, maka radiusnya 55,4 $\mathrm{km}$ dari titik koordinat. Bila dilihat dari logika ini dan dibandingkan dengan hasil temuan Dahlia Haliah Ma'un di atas, nilai ibtiyat paling tinggi bisa digunakan dalam perhitungan waktu salat adalah 4 menit dengan jarak radius 110,8 $\mathrm{km}$ dari titik koordinat perhitungan. Bila lebih dari 4 menit, maka akan bermasalah dengan waktu Isya dan Subuh yang tidak boleh selisih lintang lebih dari 1 derajat.

\section{D.Jadwal Salat Sepanjang Masa Abu Muhammad Isa Mulieng}

Jadwal salat sepanjang masa yang disusun oleh Abu Muhammad Isa Mulieng pada awalnya hanya tulisan tangan dikertas sederhana dari hasil perhitungannya (Lihat gambar 1). Setelah selesai jadwal salat ditulis, kemudian disalin oleh yang berminat dengan menggunakan mesin ketik untuk diperbanyak. Setelah jadwal salat disalin, kemudian diperbesar ukurannya dengan cara difoto kopy pada kertas ukuran besar, dibingkai dan dipajang di dinding masjid untuk dipedomani setiap hendak melakukan azan (Lihat gambar 2). Menurut Mustafa M.Isa22 selaku anaknya yang mewarisi ilmu falak dan juga Dayah Darul Falah setelah Abu Muhammad Isa meninggal, jadwal salat itu ditulis sekitar tahun 1984 untuk keperluan praktis masyarakat Aceh Utara dan sekitarnya.

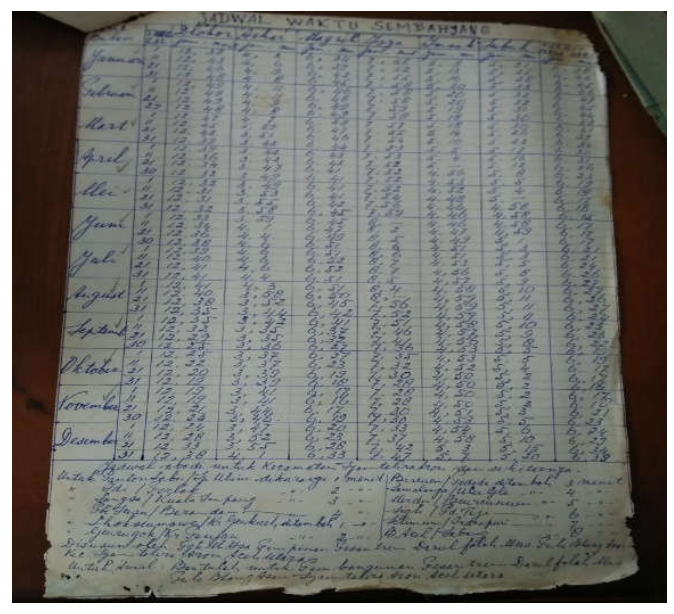

Gambar 1. Jadwal salat sepanjang masa Abu Muhammad Isa hasil tulis tangan

${ }^{22}$ Mustafa M. Isa, Biografi Muhammad Isa, 17 September 2019, Dayah Darul Falah, Aceh Utara. 


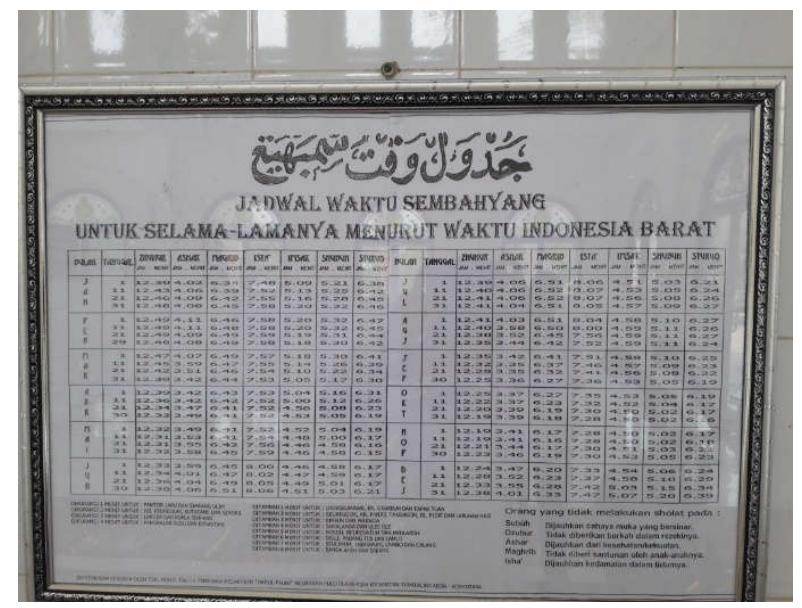

Gambar 2. Jadwal salat sepanjang masa Abu Muhammad Isa hasil cetak.

Dari gambar nomor 1 dan 2 di atas, ada beberapa hal yang perlu dijelaskan. Pertama, nama jadwal salat adalah "Jadwal waktu sembahyang untuk selamalamanya menurut Waktu Indonesia Barat". Penggunaan kata "selama-lamanya" meunjuki jadwal salat ini bisa digunakan sepanjang tahun di setiap tahu-tahun berikutnnya dan hal ini bisa dibuktikan dimana jadwal salat ini masih digunakan di beberapa masjid di seputaran Aceh Utara. Penggunaan kata "Waktu Indonesia Barat" sangat penting untuk dicatat dalam menjelajah kreativiatas dan visioner Abu Muhammad Isa dalam bidang ilmu falak, dimana saat itu masih maraknya jadwal salat yang masih menggunakan standar waktu lokal atau jam istiwak. Dalam jadwal salat ini yang dimaksud Waktu Indonesia Barat tentunya mengacu kepada Keputusan Presiden No. 243 Tahun 1963 dengan titik simpul WIB adalah bujur $105^{\circ}$ BT, tidak mungkin mengacu kepada standar WIB sekarang yang ditetapkan pada tahun 1987.

Kedua, penyusunan jadwal salat ini bertujuan untuk mengisi kelangkaan jadwal salat di Aceh, dengan cara konversi dari titik perhitungan ke beberapa kota di seluruh Aceh tentunya sangat membantu dan berguna bagi masyarakat Aceh saat itu. Konversi dilakukan dengan mempertimbangkan selisih nilai bujur saja dengan cara menambahkan waktu dalam sekala menit ke daerah barat dari titik perhitungan dan mengurangi waktu ke daerah timur dari titik perhitungan. Hal ini bisa dilihat pada gambar 2 di atas, dimana ada tersebut nama-nama kota dan kabupaten di Aceh dalam pemberlakuan jadwal salat. 
Dalam jadwal salat ini titik koordinat yang digunakan tidak tertulis, namun dari hasil wawancara dengan Mustafa M.Isa dapat dipastikan koordinat yang dipakai adalah lokasi Dayah Darul Falak. ${ }^{23}$ Pernyataan ini diperkuat oleh tulisan pada jadwal salat sepanjang masa (Lihat gambar 1) dalam pemberlakuan hasil perhitungan untuk wilayah Syamtalira Aron yang merupakan wilayah Dayah Darul Falah didirikan atau berdomisili, dan diperkuat juga dengan tulisan pemberlakuan jadwal salat dikurangi 1 menit untuk daerah Panton Labu dan ditambah 1 menit untuk Lhokseumawe (Lihat gambar 2). Secara logika dapat diterima dan meyakinkan, karena Dayah Darul Falah berada di antara dua kota tersebut dengan koordinat $05^{\circ} 06^{\prime} 19^{\prime \prime} \mathrm{LU}, 97^{\circ} 16^{\prime} 13^{\prime \prime}$ BT. ${ }^{24}$

Ketiga, Perhitungan dilakukan peloncatan 10 hari, artinya dalam jadwal salat tidak tertulis setiap hari dalam setiap bulan, hanya menggunakan rentang waktu dalam interval 10 hari. Ini bisa dilihat dalam dua gambar di atas dimana dalam setiap bulan hanya disajikan 4 hari yaitu tanggal 1, 11, 21, dan 31. Untuk melihat keakuratan hasil jadwal salat ini, penulis membandingkan dengan hasil perhitungan pogram Accurate Time. Aplikasi ini yang tergolong sangat akurat saat ini karena menggunakan algoritma VSOP87 yang merupakan algoritma paling akurat saat ini dalam menentukan posisi matahari. ${ }^{25}$

Sebelum dibandingkan, perlu digaris bawahi bahwa perbandingan ini hanya dilakukan untuk melihat konteks relevansi pemakaian jadwal salat Abu Muhammad Isa yang masih dipakai sampai saat ini dengan usia lebih kurang 35 tahun. Perbandingan ini tidak wajar dalam konteks keakuratan hasil perhitungan, karena bisa dipastikan di era 80 -an data astronomis tidak seakurat dan semudah hari ini untuk didapati yang tentunya sangat berpengaruh dalam keakuratan sebuah hasil perhitungan ilmu falak.

\footnotetext{
${ }^{23}$ Mustafa M. Isa, Biografi Muhammad Isa, 17 September 2019, Dayah Darul Falah, Aceh Utara.

${ }^{24}$ Koordinat ini diambil melalui Google Earth.

25 Rinto Anugraha, Mekanika Benda Langit (Yogyakarta: MIPA UGM, 2012). h. 157
} 
Tabel 2.

Perbandingan Akurasi Jadwal Waktu Salat

\begin{tabular}{|c|c|c|c|c|c|}
\hline 21 Maret 1984 & Zuhur & Asar & Magrib & Isya & Subuh \\
\hline Abu Muhammad Isa & 12.42 & 15.51 & 18.46 & 19.54 & 05.22 \\
\hline Accurate Time & 12.40 .08 & 15.48 .46 & 18.43 .33 & 19.52 .31 & 05.19 .50 \\
\hline selisih & 00.01 .52 & 00.02 .14 & 00.02 .27 & 00.01 .59 & 00.02 .10 \\
\hline 21 Maret 2019 & 12.40 .16 & 15.49 .09 & 18.43 .36 & 19.52 .34 & 05.20 .01 \\
\hline Selisih T.1984-2019 & 00.00 .08 & 00.00 .23 & 00.00 .03 & 00.00 .03 & 00.00 .11 \\
\hline
\end{tabular}

Dari tabel nomor 1 di atas dapat dijelaskan bahwa ada selisih hasil perhitungan waktu salat antara jadwal salat Abu Muhammad Isa dengan hasil perhitungan Accurate Time lebih lambat rata-rata 2 menit. Bila dilihat dari segi penggunaan, jadwal salat sepanjang masa Abu Muhammad Isa masih bisa digunakan hanya untuk wilayah Aceh Utara saja, mengingat hasil jadwal salat Abu Muhammad Isa lebih lambat dari yang seharusnya, yang menjadi masalah dalam berpedoman terhadap jadwal salat bila lebih cepat samapi 2 menit dari waktu yang seharusnya.

Perbedaan ini sangat wajar dan menurut penulis ada dua faktor yang saat itu belum bisa ditemukan secara akurat seperti saat ini. Pertama nilai koordinat yang menjadi acuan perhitungan saat itu masih sangat sederhana, bila boleh dicocokkan, hasil jadwal salat sepanjang masa ini lebih cocok di titik koordinat $97^{\circ} \mathrm{BT}, 05^{\circ} \mathrm{LU}$. Untuk akurasi daerah lain sebagaimana tertulis dalam konversi jadwal salat Abu Muhammad Isa, penulis tidak menganalisa lagi, karena sudah jadi kesepakatan ahli falak bahwa jadwal salat tidak akurat dengan cara konversi untuk daerah lain.

Kedua data matahari seperti deklinasi matahari dan equtor of time masih sangat sederhana. Bila dua foktor ini diselesaikan, maka hasilnya akan sama dengan hasil perhitungan modern. Untuk penggunaan istilah selama-lamanya juga tidak ada masalah, hal ini bisa dibuktikan selisih hasil perhitungan dari 35 tahun itu hanya hitungan detik, yaitu paling tinggi 23 detik. Selisih ini tentunya bisa diabaikan bila dibandingkan dengan nilai ibktiyat yang dipakai sampai 2 menit. Secara ideal, jadwal salat harus memenuhi 3 unsur. Pertama, jadwal salat disusun untuk satu kota dengan koordinat yang akurat dan perhitungan yang tepat. Kedua, jadwal salat yang 
digunakan bukan hasil konversi dari daerah lain, karena akan berbeda hasil perhitungan antara satu wilayah dengan wilayah lain. Ketiga, jadwal salat dikeluarkan oleh lembaga resmi atau individu yang ahli dalam bidang ilmu falak. ${ }^{26}$

\section{E. Kesimpulan}

Berdasarkan dari penjelasan di atas dapat diambil kesimpulan bahwa jadwal waktu salat sepanjang masa karya Abu Muhammad Iasa Mulieng sangat inovatif dan visioner di masanya, dimana jadwal salat sepanjang masa yang disusun dengan konsep konversi dalam bentuk pemberlakuan untuk daerah sekitar sangat dibutuhkan dan berguna bangi masyarakat. Jadwal salat ini termasuk sangat aktual di masanya karena berpatokan pada waktu standar Waktu Indonesia Barat (GMT +7). Penyusunan jadwal waktu salat berdasarkan patokan zona waktu bisa dimasukkan dalam jenis lain dalam jadwal salat selain dua jenis yang telah disebutkan di atas, sehingga bisa dibuktikan bahwa jenis jadwal salat ada empat, yaitu jadwal salat konversi, jadwal salat tunggal, jadwal salat berpatokan pada zona waktu, jadwal salat berpatokan pada waktu istiwak. Setiap jadwal salat hanya bisa dipedomani dalam radius 27,7 kilometer untuk yang menggunakan ibktiyat 1 menit dan radius 55,4 kilometer dari titik perhitungan dengan nilai ibktiyat 2 menit.

Jadwal salat Abu Muhammad Isa Mulieng masih relevan untuk dipedomani dalam radiun 55,4 kilometer dari titik perhitungan, yaitu dayah Darul Falah. Hal ini dikarenakan nilai ibktiyat yang digunakan adalah 2 menit dan hasil perbandingan dengan perhitungan modern, hasilnya lebih lambat sekitar 2 menit dari yang seharusnya.

\footnotetext{
$* * * * * * * * *$
}

${ }^{26}$ Arwin Juli Rakhmadi Butar-Butar, "Kajian Ilmu Falak di Indonesia: Kontribusi Syaikh Hasan Maksum dalam Bidang Ilmu Falak," Journal of Contemporary Islam and Muslim Societies 1, no. 1 (2017): 255942, https://doi.org/10.30821/jcims.v1i1.1007. 
Aktualisasi Jadwal Salat Sepanjang Masa ...

\section{Daftar Pustaka}

Anugraha, Rinto. Mekanika Benda Langit. Yogyakarta: MIPA UGM, 2012.

Ardliansyah, Moelki Fahmi. "Implementasi Titik Koordinat Tengah Kabupaten atau Kota Dalam Perhitungan Jadwal Waktu Salat." Al-Abkam 27, no. 2 (1 Desember 2017): 213. https://doi.org/10.21580/ahkam.2017.27.2.1981.

Badan Hisab dan Rukyat, Departemen Agama. Almanak Hisab Rukyat. Jakarta: Proyek Pembinaan Badan Peradilan Agama Islam, 1981.

Butar-Butar, Arwin Juli Rakhmadi. "Kajian Ilmu Falak di Indonesia: Kontribusi Syaikh Hasan Maksum dalam Bidang Ilmu Falak." Journal of Contemporary Islam and Muslim Societies 1, no. 1 (2017): 255942. https://doi.org/10.30821/jcims.v1i1.1007. . Waktu Salat Menurut Fikih dan Astronomi. Medan: LPPM UISU, 2016.

Departemen Agama RI. Pedoman Penentuan Jadwal Waktu Shalat Sepanjang Masa. Jakarta: Departemen Agama RI, 1994.

Djamaluddin, Thomas. Menggagas Fiqih Astronomi: Tela'ah Hisab-rukyat dan Pencarian Solusi Perbedaan Hari Raya. 1 ed. Bandung: Kaki Langit, 2005.

Hamdani, Fahmi Fatwa Rosyadi Satria, dan Laksmiyanti Annake Harijadi Noor. "The Dawn Sky Brightness Observations in the Preliminary Shubuh Prayer Time Determination." QIJIS (Qudus International Journal of Islamic Studies) 6, no. 1 (2 Juli 2018): 25-38. https://doi.org/10.21043/qijis.v1i1.2870.

Jayusman, Jayusman. "Akurasi Nilai Waktu Ihtiyath Dalam Perhitungan Awal Waktu Salat." $A S A S$ 11, no. $01 \quad$ (13 Agustus 2019): 78-93. https://doi.org/10.24042/asas.v11i01.4644.

, "Urgensi Ihtiyath dalam Perhitungan Awal Waktu Salat." $A L-' A D A L A H 10$, no. 1 (2012): 279-90. https://doi.org/10.24042/adalah.v10i1.269.

Junaidi, Ahmad. "Penyatuan Zona Waktu Indonesia Dan Implikasinya Pada Waktu Ibadah." Justicia Islamica 9, no. 2 (2012). https://doi.org/10.21154/justicia.v9i2.350.

Khazin, Muhyiddin. Ilmu Falak dalam Teori dan Praktik, Perbitungan arah kiblat, waktu salat, awal bulan dan gerhana. Yogyakarta: Buana Pustaka, 2004.

Ma'un, Dahlia Haliah. “Jadwal Salat Sepanjang Masa Di Indonesia (Studi Akurasi Dan Batas Perbedaan Lintang Dalam Konversi Jadwal Salat)." Disertasi, IAIN Walisongo, 2013. http://eprints.walisongo.ac.id/23/.

. "Waktu Shalat: Pemaknaan Syar'I ke Dalam Kaidah Astronomi”, Istinbath: Jurnal Hukum Islam, 14, no. 2, 2015

Mustafa M. Isa. Biografi Muhammad Isa, 17 September 2019. Dayah Darul Falah, Aceh Utara.

Rohmah, Nihayatur. "Penentuan Waktu Shalat Isya dan Shubuh Dengan Aplikasi Fotometri." UIN Walisongo Semarang, 2011. 
Rahmi, Nailur. "Penyatuan Zona Waktu dan Pengaruhnya terhadap Penetapan Awal Waktu Shalat." Juris 13, no. 1 (2014): 75-83. https://doi.org/10.1234/juris.v13i1.1130.

Rojak, Encep Abdul. Amrullah Hayatuddin, dan Muhammad Yunus, "Koreksi Ketinggian Tempat terhadap Fikih Waktu Salat: Analisis Jadwal Waktu Salat Kota Bandung", Al-Abkam, 27, no. 2, 2017

Suroya, Nila. Uji Akurasi Pedoman Waktu Shalat Sepanjang Masa Karya Saädoéddin Djambek, Skripsi, Semarang: IAIN Walisongo, 2013

Wahab, Murdani Bin Abdul. "Murdani bin Abdul Wahab: Biografi Ahli Falak Aceh; Teungku Muhammad Isa Mulieng, Aron. (1927-1997 M)." Murdani bin Abdul Wabab (blog), 2017. http://murdanialasyi.blogspot.com/2017/01/biografi-ahli-falak-acehteungku.html.

Z, Akhina. "Zona Waktu di Indonesia Pernah Berubah 9 Kali. Gimana Ceritanya?" Good News From Indonesia, 17 Juni 2018. https://www.goodnewsfromindonesia.id/2018/06/17/zona-waktu-diindonesia-pernah-berubah-9-kali-gimana-ceritanya. 
Aktualisasi Jadwal Salat Sepanjang Masa ... 